\title{
An evidence and consensus based guideline for acute diarrhoea management
}

\author{
K Armon, T Stephenson, R MacFaul, P Eccleston, U Werneke
}

\begin{abstract}
Objective-To develop an evidence and consensus based guideline for the management of the child who presents to hospital with diarrhoea (with or without vomiting), a common problem representing $16 \%$ of all paediatric medical attenders at an accident and emergency department. Clinical assessment, investigations (biochemistry and stool culture in particular), admission, and treatment are addressed. The guideline aims to aid junior doctors in recognising children who need admission for observation and treatment and those who may safely go home. Evidence-A systematic review of the literature was performed. Selected articles were appraised, graded, and synthesised qualitatively. Statements on recommendation were generated.

Consensus-An anonymous, postal Delphi consensus process was used. A panel of 39 selected medical and nursing staff were asked to grade their agreement with the generated statements. They were sent the papers, appraisals, and literature review. On the second and third rounds they were asked to re-grade their agreement in the light of other panellists' responses. Consensus was predefined as $83 \%$ of panellists agreeing with the statement.
\end{abstract}

Recommendations-Clinical signs useful in assessment of level of dehydration were agreed. Admission to a paediatric facility is advised for children who show signs of dehydration. For those with mild to moderate dehydration, estimated deficit is replaced over four hours with oral rehydration solution (glucose based, 200$250 \mathrm{mOsm} / \mathrm{l}$ ) given "little and often". A nasogastric tube should be used if fluid is refused and normal feeds started following rehydration. Children at high risk of dehydration should be observed to ensure at least maintenance fluid is tolerated. Management of more severe dehydration is detailed. Antidiarrhoeal medication is not indicated.

Validation-The guideline has been successfully implemented and evaluated in a paediatric accident and emergency department.

(Arch Dis Child 2001;85:132-142)

Keywords: diarrhoea; gastroenteritis; Delphi consensus; guideline

Diarrhoea is defined as a change in bowel habit for the individual child resulting in substantially more frequent and/or looser stools. Acute diarrhoea, most frequently the result of infectious intestinal disease (IID), represents a major cause of consultations in general practice. Djuretic et al estimated that each year there are 526000 consultations in children age under 5 years with IID. ${ }^{1}$ Using 1994 population data this equates to about 1 in 6 children per year consulting their general practitioner with an episode of IID, though this figure may be an overestimate as some may attend more than once. Sixteen per cent of all paediatric medical presentations to accident and emergency departments are for children with diarrhoea, with or without vomiting. ${ }^{2}$ Hospital admissions for children with gastroenteritis rose by about $6 \%$ from 1989 to 1994 and currently account for approximately $7 \%$ of all paediatric admissions in the under 5 age group. ${ }^{3}$ In 1994 hospital admission rates of 1 child in 150 under 5 years for IID were reported and the cost of inpatient care had risen from that in 1991. Gastroenteritis admission rates are significantly higher in young children from more deprived areas. ${ }^{5}$ Children with similar severity of illness on attendance may be managed differently (unpublished data) and junior doctors make many of the initial decisions. $^{2}$

We set out to develop this guideline with the following aims: (1) to improve the process and outcome of care for children attending hospital with diarrhoea; (2) to promote consistency of care so that patients with almost identical clinical problems would be managed in the same way; and (3) to inform, educate, and improve the clinical decision making of the junior clinicians who see most of these children initially.

Scope of the guideline

The guideline deals with children who have diarrhoea, with or without vomiting, rather than with a defined diagnosis, as the guideline should assist clinicians in diagnosis prior to management of a particular condition. ${ }^{6}$ Children presenting with vomiting alone or with chronic diarrhoea (more than seven days duration) are not considered. We present a summary version of the full guideline (which can be obtained from the corresponding author, or the Archives of Disease in Childhood website, www.archdischild.com) to which reference should be made for clarification or further information. The authors assume that health care professionals will use general medical knowledge and clinical judgement in applying the recommendations in this document to the management of individual patients. These recommendations may not be appropriate for use in all circumstances. 


\section{Method of development}

Recommendations made are based on statements derived from a systematic review of published literature and refined by a three round Delphi consensus development process. The literature search used the following databases: Medline (1966 to June 1998), Embase (1980 to June 1998), and Cochrane (to June 1998). The following mesh headings and text words were used: diarrh ${ }^{\star}$; diarrhea infantile; diarrhea to 14 years; gastroenteritis; differential diagnosis; diagnos ${ }^{\star}$; incidence; prevalence; aetiology; etiology; dehydration; patient admission; fluid therapy; intravenous; intravenous treatment; rehydration solution; administration, oral; enteral nutrition; faeces; feces; lactose intolerance; enteral; differential diagnosis. General search terms for the type of study required were also used (for example, for diagnostic procedures, the search "sensitivity and specificity or predictive value of tests or diagnostic errors or screening or diagnosis or sensitivity or specificity" was used).

Explicit inclusion criteria were set: articles that addressed the clinical questions identified, a scientific review of the literature, and a review or clinical guideline written by a national body. Articles were excluded if opinion based. Included articles were critically appraised using a standard proforma, and recommendations were graded using a standard grading scheme (see Appendix). The derived statements, together with the original papers referred to ${ }^{4-67}$ and appraisals were sent to a Delphi panel consisting of 39 medical and nursing staff who regularly manage children with diarrhoea, with or without vomiting. The final guideline based on the literature review and predefined consensus agreement (agreement by at least $83 \%$ of panelists) is in the form of an algorithm (flow diagram or decision tree) shown in fig 1. Each box is numbered, and key decision points are allocated a letter, with recommendations explained in the text. Throughout, the word "admit" is defined as follows: any admission to a paediatric facility with paediatric trained staff for observation, further investigation, and management regardless of the expected length of stay.

\section{The guideline}

A: DIFFERENTIAL DIAGNOSIS OF CHILD

PRESENTING WITH DIARRHOEA

Statement - There are no published data on the relative probabilities of possible diagnoses in the child presenting to hospital with diarrhoea.

A table of differential diagnoses (table 1) is shown derived from published texts ${ }^{18}{ }^{65}(\mathrm{Vb}, \mathrm{D})$ and consensus opinion, not intended to be comprehensive, but rather to act as an aide memoir to the clinician. (Based on Level Vb evidence and Delphi consensus, Grade D recommendation.)

It is essential that the clinician recognise any life threatening causes of diarrhoea, such as intussusception $^{19}(\mathrm{Vb}, \mathrm{D})$, surgical abdomen ${ }^{21}$ $(\mathrm{Vb}, \mathrm{D})$, and haemolytic uraemic syndrome ${ }^{20}$ (III, C). Features suggestive of these conditions are identified, and although these features may occur in acute gastroenteritis the likelihood of a different aetiology is increased and should be actively sought.

Recommendation on differential diagnosis

The following clinical features should alert the clinician to look for causes other than acute viral gastroenteritis for a child's diarrhoea with or without vomiting:

- Abdominal pain with tenderness, with or without guarding $(\mathrm{Vb}, \mathrm{D})$

- Pallor, jaundice, oligo/anuria, bloody diarrhoea (III, C)

- Systemically unwell, out of proportion to the level of dehydration $(\mathrm{Vb}, \mathrm{D})$

- Shock (Vb, D).

Features are based on evidence levels shown and Delphi consensus agreement.

B: ESTIMATION OF SEVERITY OF DEHYDRATION The management of gastroenteritis consists of correction of dehydration (rehydration) and maintenance of hydration. An accurate estimate of the level of dehydration is required to achieve this end.

Statement - The severity of dehydration is most accurately assessed in terms of weight loss as a percentage of total body weight (prior to the dehydrating episode). This is the "gold standard" against which other "tests" are measured $^{25}(\mathrm{I}, \mathrm{A})$.

In a prospective cohort study of children between 3 and 18 months of age in Egypt, Duggan and colleagues ${ }^{26}$ (III) found that "prolonged skinfold", dry oral mucosa, sunken eyes, and "altered neurological status" were the best clinical signs correlating with dehydration as determined by post-rehydration weight gain. In a similarly designed study, with children under 4 years old, Mackenzie and colleagues ${ }^{27}$ (III) found "decreased skin turgor", decreased peripheral perfusion, and deep (acidotic) breathing to be the best clinical indicators of dehydration. A urea of $>6.5 \mathrm{mmol} / 1$ on serum blood sample and $\mathrm{pH}<7.35$ on blood gas were positive investigations associated with dehydration. However the sensitivity and specificity of all these signs were low.

In both studies mild to moderate dehydration on clinical assessment was found to represent weight loss of $3-5 \%$. Those with severe signs (circulatory collapse) had weight loss of 9-10\%. These studies correlate well with the WHO guidance on dehydration assessment. ${ }^{66}$

\section{Recommendation}

See table 2 for estimating level of dehydration if weight loss not available. (Level III and Delphi consensus, Grade $C$ recommendation.)

\section{C: BLOOD TESTS}

Statement-There is no direct evidence indicating when serum electrolytes should be measured in a child with diarrhoea.

The indication from cohorts of children in the UK with gastroenteritis is that derangement of electrolytes is $\operatorname{rare}^{376162}$ with $1 \%$ of admissions having hypernatraemia and no reports of hypokalaemia or hyponatraemia. Even when there is derangement of electrolytes in the 


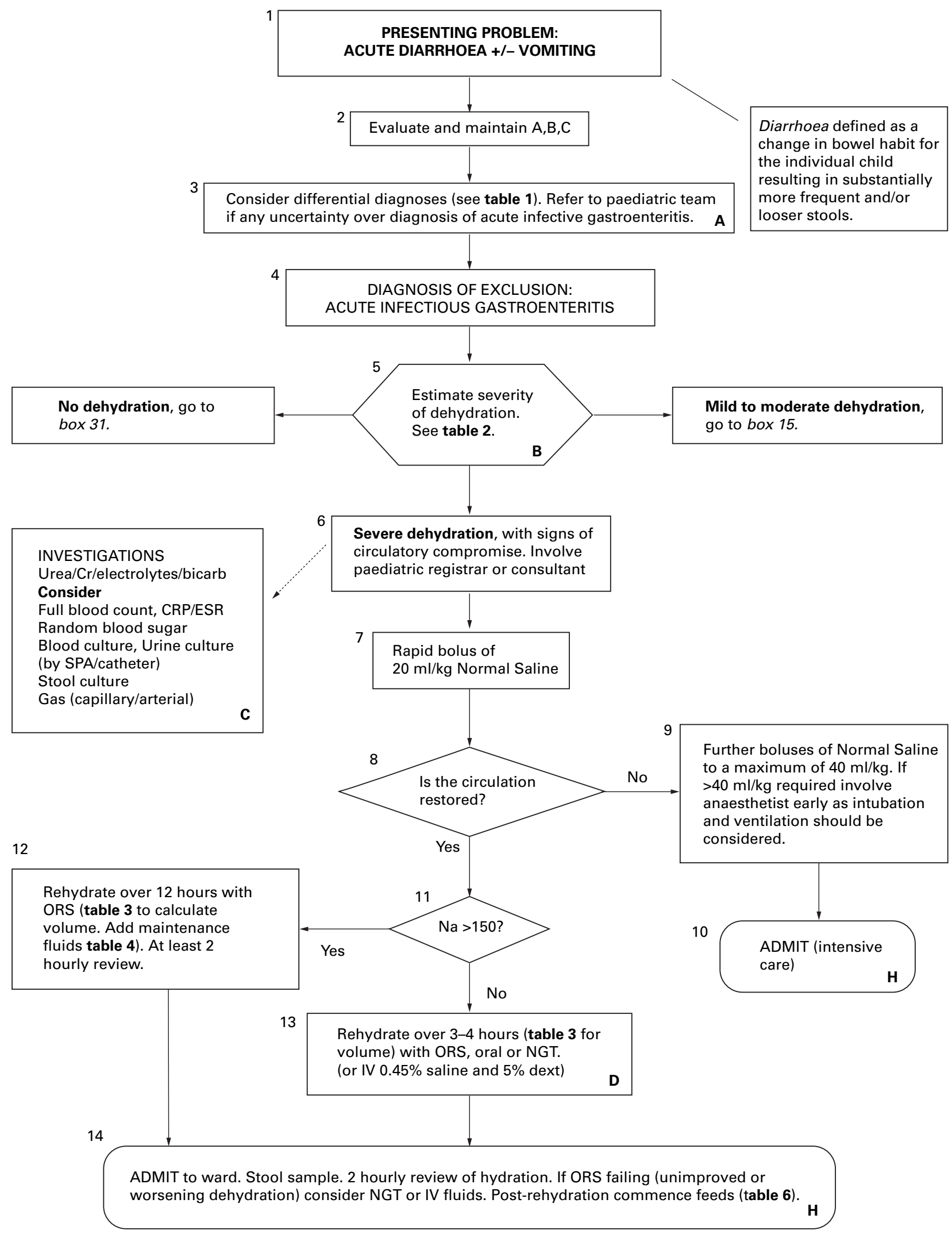

Figure 1 The final guideline. A, B, C, airway, breathing, circulation; $C R P$, c reactive protein; ESR, erythrocyte sedimentation rate; SPA, suprapubic aspirate; Ur, urea; Cr, creatinine; Elec, electrolytes; Bicarb, bicarbonate; $N a$, serum sodium (mmolll); ORS, oral rehydration solution; NGT, nasogastric tube; IV, intravenous; IVI, intravenous infusion; CHD, congenital heart disease; UE E, urea and electrolytes.

serum, this is a result of relative losses of salts and water. There will still be a total body depletion of sodium in hypernatraemic patients. ${ }^{25}$ Oral rehydration solution (ORS) with appropriate amounts of solutes and given in the correct quantity is sufficient in itself to correct electrolyte abnormalities ${ }^{41}$ (II, B). ${ }^{42}$ It is thus unnecessary to measure electrolytes in those children 


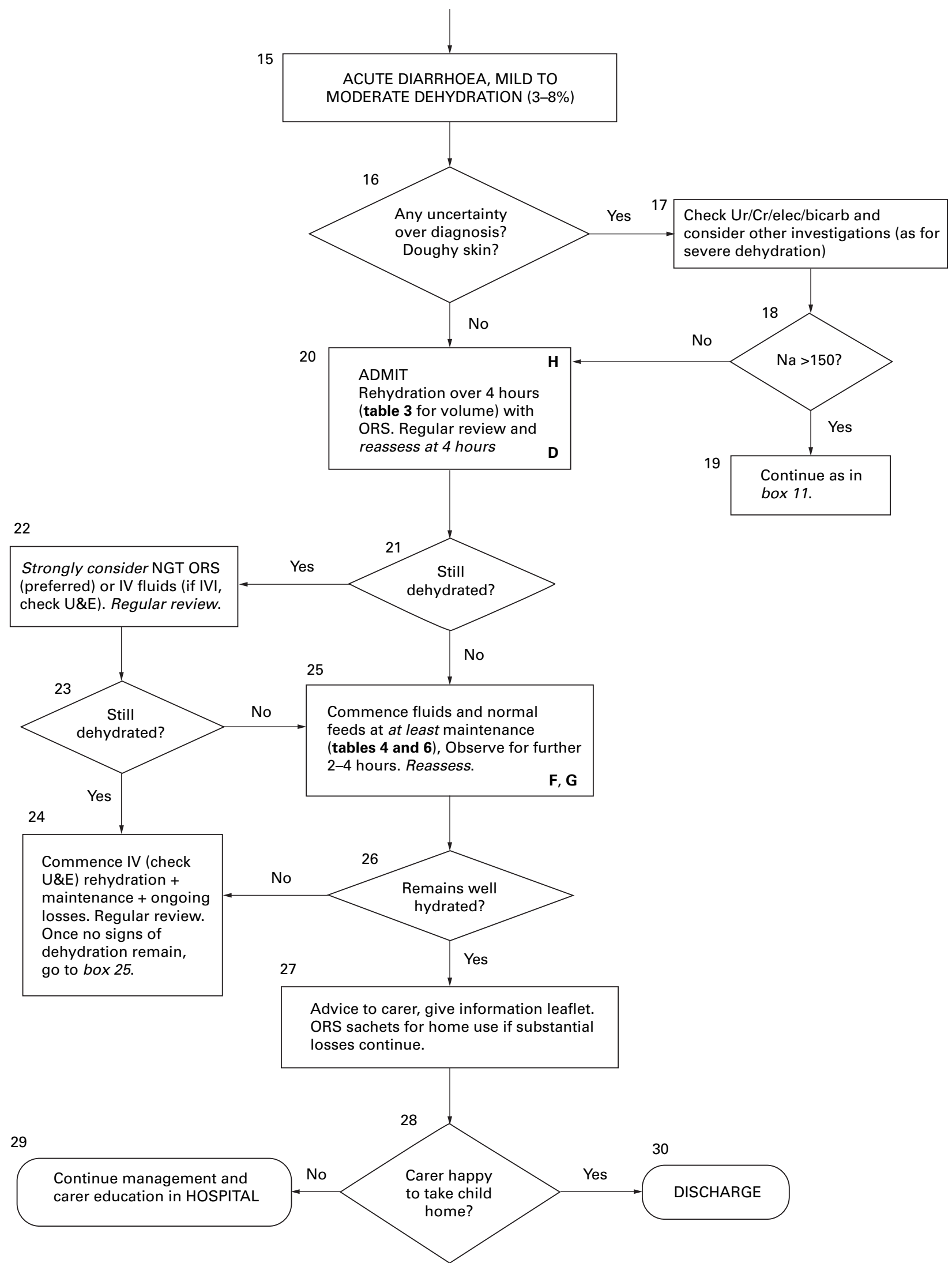

who will be rehydrated with ORS. All children having intravenous rehydration should have urea and electrolytes (U\&E) measured, as hypernatraemia will alter the rate at which intravenous rehydration fluids are given and further measurements of U\&E should be made as rehydration progresses. ${ }^{25}$ In addition the American Academy of Pediatrics (AAP) suggest in their practice parameter ${ }^{40}$ (Va, D) that electrolyte levels should be measured in moderately 


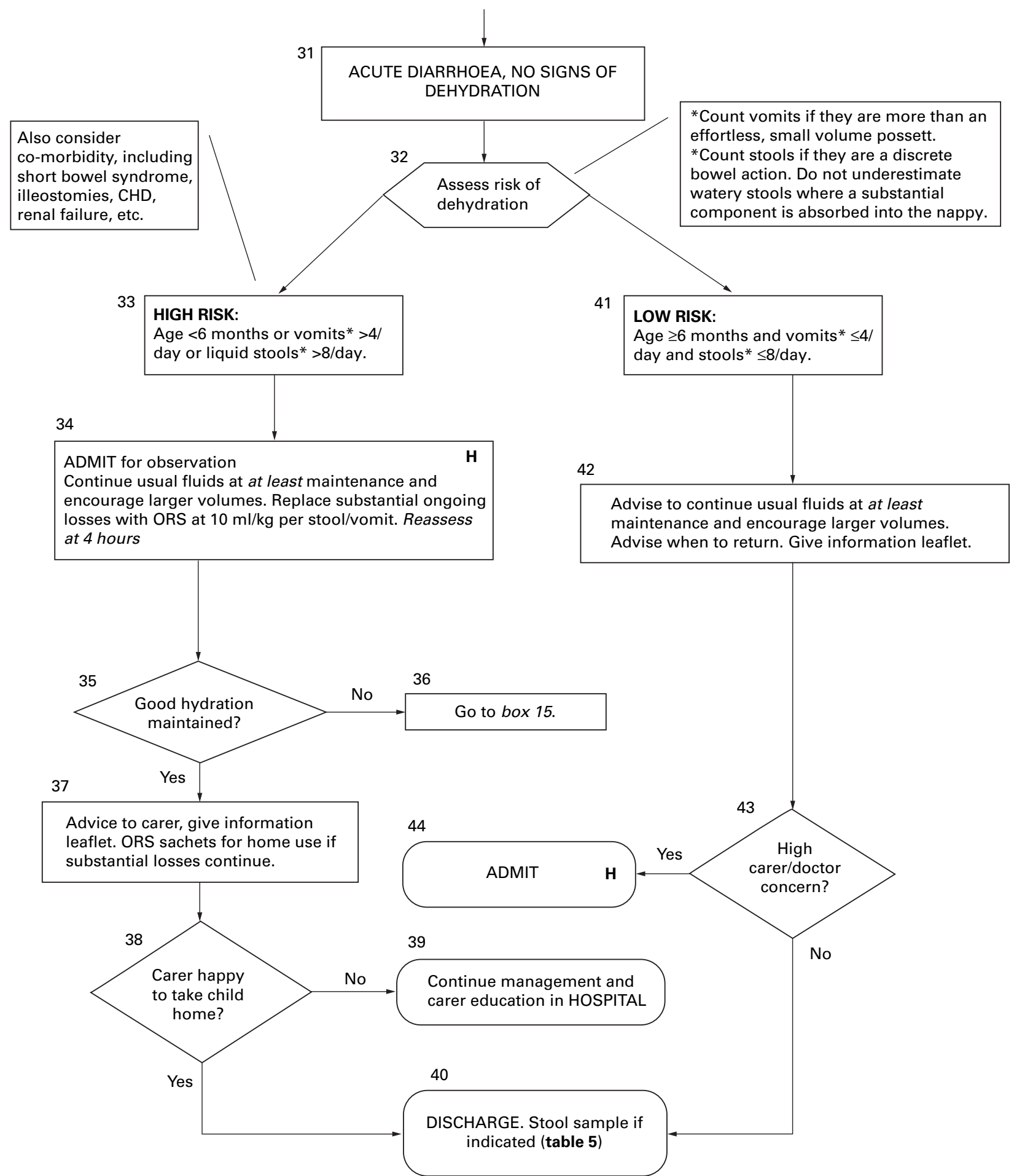

dehydrated children whose histories or physical findings are inconsistent with straightforward diarrhoeal episodes, and where a "doughy" feel to the skin may indicate hypernatraemia.

Recommendation on blood tests

The child who presents with diarrhoea, with or without vomiting, should have blood taken for urea/creatinine, electrolytes, and bicarbonate in the following circumstances:

- Severe dehydration with circulatory compromise
- Moderate dehydration where a "doughy" feel to the skin might indicate hypernatraemia

- Moderately dehydrated children whose histories or physical findings are inconsistent with straightforward diarrhoeal episodes.

(Based on Level Va evidence and Delphi consensus, Grade D recommendation.)

D: MANAGEMENT OF REHYDRATION

Following the evidence of several randomised controlled trials in the USA, Europe, and 
Table 1 Broad differential diagnosis of the child presenting with acute diarrhoea (with or without vomiting). The latter diagnoses are more likely to present chronically

\begin{tabular}{|c|c|}
\hline Category & Examples \\
\hline Infections & Enteral: viral (commonest cause), bacterial, parasitic \\
\hline & Non-enteral infections (urinary tract infection, pneumonia, otitis media)-vomiting predominates \\
\hline Surgical & Appendicitis, intussusception, obstruction, short bowel syndrome \\
\hline Systemic illness & $\begin{array}{l}\text { Endocrinopathy (diabetes, hyperthyroidism, congenital adrenal hyperplasia, Addison's disease, } \\
\text { hypoparathyroidism), immunodeficiency }\end{array}$ \\
\hline Antibiotic associated & While taking antibiotics and rarely pseudomembranous colitis \\
\hline Miscellaneous & $\begin{array}{l}\text { Constipation with overflow, toxins, haemolytic-uraemic syndrome, toddler diarrhoea, child abuse } \\
\text { (Munchausen by proxy, sexual) }\end{array}$ \\
\hline Dietary disturbance & Food allergy/intolerance (lactose, cows' milk protein), starvation stools \\
\hline Malabsorption & Cystic fibrosis, coeliac disease \\
\hline Inflammation & Ulcerative colitis/Crohn's disease, Hirschsprung's enterocolitis \\
\hline Idiopathic/psychogenic & Irritable bowel syndrome \\
\hline
\end{tabular}

NB. The following features may be indicative of diagnoses other than acute viral gastroenteritis ${ }^{\mathbf{A}}$ : abdominal pain with tenderness/ guarding and/or bilious vomiting (?surgical); pallor, jaundice, oligoanuria, bloody stool (?haemolytic-uraemic syndrome); systemically unwell, out of proportion to the level of dehydration (other infections, surgical, congenital adrenal hyperplasia, etc); shock.

developing countries ${ }^{49} 515254$ (II, B), it is acknowledged that ORS is quicker in the correction of dehydration and acidosis and safer than intravenous therapy ${ }^{25}$ (I, A). ${ }^{63}$ The overall failure rate of oral rehydration therapy (ORT, defined as the persistence or recurrence of signs of dehydration and other clinical indications requiring the need for intravenous rehydration) was $3.6 \%$ (95\% confidence interval 1.4 to 5.8$).{ }^{63}$ Moreover the use of ORT appears to reduce the risk of seizure during correction of hypernatraemic dehydration ${ }^{52}$ (II, B).

Recommendation in mild-moderate dehydration

- Children who have mild-moderate dehydration secondary to acute gastroenteritis should have their deficit estimated (3$8 \%)$ and replaced with ORS (30-80 $\mathrm{ml} / \mathrm{kg}$ ) given "little and often" over 3-4 hours, whenever this is practically possible. ${ }^{25} 404463$ (Level I and Delphi consensus, Grade $A$ recommendation.) (An attempt was made to define "little and often" further. The literature discusses the correct administration of ORS and recommends that it be given in $5 \mathrm{ml}$ aliquots every $1-2$ minutes. Only if this is well tolerated with no vomiting may the size of the aliquots be increased, with decreasing frequency. ${ }^{2541426364}$ However this regime was thought to be too labour intensive for the UK by the Delphi panelists and did not achieve consensus.) (Definition of "whenever practically possible": this implies that the child's carer is willing and able to carry this out under supervision.)

- Where the child's carer is not willing and able to carry this out, or when it is required overnight, rehydrate by continuous nasogastric tube infusion (preferred) or intravenous infusion. (Level $\mathrm{Va}$ and Delphi consensus, Grade $D$ recommendation.)

- Regularly assess success of rehydration (for example, two hourly). If no improvement in clinical signs of dehydration or worsening signs, consider nasogastric tube or intravenous infusion. (Level $\mathrm{Va}$ and Delphi consensus, Grade D recommendation.)
E: COMPOSITION OF ORS

In the 1970s the WHO adopted a glucoseelectrolyte solution that contained $90 \mathrm{mmol} / \mathrm{l}$ of sodium for the treatment of diarrhoea. Since then there have been many controlled trials looking at the ideal concentration of electrolytes and carbohydrate in ORS. A recent multicentre trial in four developing countries found that reduced osmolarity ORS (224 mmol/l) had advantages over standard ORS (311 $\mathrm{mmol} / \mathrm{l}$ ) in the treatment of non-cholera diarrhoea $^{46}$ (II, B). In developed countries diarrhoea tends to be isotonic (mainly rotavirus induced) and the European Society of Paediatric Gastroenterology and Nutrition (ESPGAN) ${ }^{44}$ published guidelines on the ideal composition of ORS for children of Europe. Since this publication, studies from Finland ${ }^{47}$ (II, B) and a multicentre $\operatorname{trial}^{46}$ (II, B) have confirmed that reduced osmolarity ORS is preferable in European children. See table 8 for the composition of ORS recommended and those commercially available.

A recent meta-analysis of 13 clinical trials examining the effect of rice based ORS on total stool output and duration of diarrhoea showed that there appeared to be some benefit in those with cholera, but in those with non-cholera diarrhoea no benefit was shown ${ }^{48}$ (I, A).

\section{Recommendation on the composition of ORS}

- ORS used for rehydration of children with acute gastroenteritis in the UK should contain: $60 \mathrm{mmol} / 1$ sodium, $20 \mathrm{mmol} / 1$ potassium, $\geqslant 25 \mathrm{mmol} / 1$ chloride, and 74-111 $\mathrm{mmol} / \mathrm{l}$ glucose. (Commercial solutions conforming to this include Dioralyte and Diocalm Junior.) (Level I and Delphi consensus, Grade A recommendation.)

\section{F: MAINTENANCE OF HYDRATION/PREVENTION OF} DEHYDRATION

The child who was not dehydrated and the child who is no longer dehydrated following rehydration should be allowed free fluids, and be encouraged to drink more than usual. ${ }^{25} 40$ Tables 3 and 4 show standard methods for calculating ORS requirements. Table 5 suggests when to send a stool sample to the laboratory. 
Table 2 Assessment of severity of dehydration (if in doubt err by overestimating \% dehydration $)^{\mathbf{B}}$

\begin{tabular}{|c|c|c|}
\hline $\begin{array}{l}\text { No dehydration } \\
\text { (less than } 3 \% \text { weight loss) }\end{array}$ & $\begin{array}{l}\text { Mild-moderate dehydration } \\
\text { ( } 3-8 \% \text { weight loss) } \\
\text { (ordered by increasing severity) }\end{array}$ & $\begin{array}{l}\text { Severe dehydration } \\
(\geqslant 9 \% \text { weight loss })\end{array}$ \\
\hline \multirow[t]{2}{*}{ No signs } & $\begin{array}{l}\text { Dry mucous membranes (be } \\
\text { wary in the mouth breather) } \\
\text { Sunken eyes (and minimal or no } \\
\text { tears) }\end{array}$ & $\begin{array}{l}\text { Increasingly marked signs from } \\
\text { the mild-moderate group plus: } \\
\text { Decreased peripheral perfusion } \\
\text { (cool/mottled/pale peripheries; } \\
\text { capillary refill time }>2 \mathrm{sec} \text { ) }\end{array}$ \\
\hline & $\begin{array}{l}\text { Diminished skin turgor (pinch } \\
\text { test } 1-2 \mathrm{sec} \text { ) } \\
\text { Altered neurological status } \\
\text { (drowsiness, irritability) } \\
\text { Deep (acidotic) breathing }\end{array}$ & Circulatory collapse \\
\hline
\end{tabular}

Signs are ordered in each column by severity.

If a pre-illness accurate weight is available, calculate deficit from weight loss.

Pinch test: Pinch skin of abdomen. Skin recoils instantly $=$ normal, $1-2 \mathrm{sec}=$ mild-moderate, $>2$ $\sec =$ severe.

Table 3 Calculation of oral rehydration solution requirements in the dehydrated child with acute gastroenteritis ${ }^{\mathbf{D}}$

Mild-moderate (3-8\%) dehydration: $\quad 30-80 \mathrm{ml}$ per kg in 4 hours
Severe dehydration $(\geqslant 9 \%):$
Practical points:
Children who are dehydrated are thirsty and do not normally refuse ORS
Give fluid little and often. If the child is vomiting, decrease volumes and increase frequency
(every 5-10 minutes)
Where carers are not willing/able to do this under supervision (or child is asleep), then
rehydrate by nasogastric tube ${ }^{\mathrm{E}}$
Suitable ORS are Dioralyte, Diocalm Junior, or Electrolade

Table 4 Calculation of ORS maintenance fluid requirements ${ }^{\mathrm{F}}$

$100 \mathrm{ml}$ per $\mathrm{kg}$ per 24 hours for the first $10 \mathrm{~kg}$ of body weight

Added to: $50 \mathrm{ml} / \mathrm{kg} /$ day for the next $10 \mathrm{~kg}$ of body weight

Added to: $20 \mathrm{ml} / \mathrm{kg} /$ day for remaining $\mathrm{kg}$ of body weight

For example, a $22 \mathrm{~kg}$ child has maintenance requirements of: $(10 \times 100)+(10 \times 50)+(2 \times$ 20) $=1540 \mathrm{ml} / 24$ hours

Ongoing losses: these requirements should be supplemented if the child has frequent or

substantial watery stools or vomits, by an additional $10 \mathrm{ml} / \mathrm{kg}$ per stool/vomit

Table 5 When to send a stool to the laboratory for microscopy, culture, sensitivity, and virology in acute diarrhoea

A history of blood with or without mucus in the stool

Systemically unwell, severe or prolonged diarrhoea

A history suggestive of food poisoning

Recent travel abroad
Table 7 Guide to drug treatment in acute gastroenteritis ${ }^{\mathbf{G}}$

\begin{tabular}{ll}
\hline Antidiarrhoeal: & $\begin{array}{l}\text { Infants and children should not be } \\
\text { treated with antidiarrhoeal agents }\end{array}$ \\
Antibiotics: & $\begin{array}{l}\text { Patients with invasive Salmonella typhi, } \\
\text { shigella, amoebiasis, and giardiasis } \\
\text { should be treated with antibiotics. } \\
\text { Consider in infants <6 months with } \\
\text { other salmonella infections, those who } \\
\text { are systemically unwell, and the } \\
\text { immunocompromised }\end{array}$ \\
\hline
\end{tabular}

In children with acute gastroenteritis who are formula fed, the vast majority (over 80\%) can be successfully managed following rehydration with continued feeding of undiluted non-human milks ${ }^{55}$ (I, A). This is now recommended practice, including the introduction of age appropriate diets in children who are weaned..$^{25} 4567$

\section{Recommendation on refeeding (see table 6)}

- Breast feeding children should continue to breast feed through the rehydration and maintenance phases of their acute gastroenteritis illness. (Level III and Delphi consensus, Grade $C$ recommendation.)

- In the dehydrated child with gastroenteritis who is normally formula fed, feeds should stop during rehydration and restart as soon as the child is rehydrated (four hours). (Level I and Delphi consensus, Grade A recommendation.)

\section{H: CRITERIA FOR ADMISSION OF CHILDREN WITH} GASTROENTERITIS

Statement - There are no published trials comparing outpatient with inpatient management, nor are there any recommendations made by eminent bodies.

Recommendations for admission

The following reached Delphi consensus agreement.

- Children presenting to hospital with acute gastroenteritis who are severely dehydrated should be admitted to hospital.

Table 6 Management of feeding during acute gastroenteritis $^{\mathbf{G}}$

- Those children with mild-moderate dehydration should be observed in a hospital paediatric facility for a period of at least 6 hours to ensure successful rehydration (3-4 hours) and maintenance of hydration (2-3 hours).

- Those children at high risk of dehydration on the basis of young age (infants $<6$ months $^{22} 23$ (III, C)), high frequency of watery stools (more than eight per 24 hours $^{22} 24$ (III, C)) or vomits (more than four per 24 hours $^{22} 24$ (III, C)) should be observed in a hospital paediatric facility for at least 4-6 hours to ensure adequate maintenance of hydration.

- Those children whose parents or carers are thought to be unable to manage the child's condition at home successfully should be admitted to hospital.

G: REFEEDING FOLLOWING REHYDRATION

Good evidence exists to show that children who are breast fed should continue breast feeding throughout the rehydration and maintenance phases of their therapy ${ }^{2456}$ (III, C). In so doing they reduce the risk of dehydration, pass smaller volumes of stool, and recover quicker.

There is evidence from several randomised controlled trials that antidiarrhoeal and antimotility agents are not clinically beneficial in 
Table 8 Composition of fluids for intravenous and oral rehydration in acute gastroenteritis

\begin{tabular}{|c|c|c|c|c|c|c|}
\hline & $\begin{array}{l}\text { Osmolality } \\
(\mathrm{mOsm} / \mathrm{l}\end{array}$ & $\begin{array}{l}\text { Glucose } \\
\text { (mmol/l) }\end{array}$ & $\begin{array}{l}\text { Sodium } \\
(\mathrm{mmol} / \mathrm{l})\end{array}$ & $\begin{array}{l}\text { Chloride } \\
\text { (mmol/l }\end{array}$ & $\begin{array}{l}\text { Potassium } \\
(\text { mmolll) }\end{array}$ & $\begin{array}{l}\text { Base } \\
(\text { mmol/l) }\end{array}$ \\
\hline \multicolumn{7}{|l|}{ Oral } \\
\hline ESPGAN & $200-250$ & $74-111$ & 60 & $\geqslant 25$ & 20 & Citrate 10 \\
\hline Dioralyte & 240 & 90 & 60 & 60 & 20 & Citrate 10 \\
\hline Diocalm Jr & 251 & 111 & 60 & 50 & 20 & Citrate 10 \\
\hline Rehidrat & 335 & $91^{\star}$ & 50 & 50 & 20 & $\begin{array}{l}\text { Bicarb } 20 \\
\text { Citrate } 9\end{array}$ \\
\hline Electrolade & 251 & 111 & 50 & 40 & 20 & Bicarb 30 \\
\hline $\begin{array}{l}\text { WHO ORS } \\
\text { Intravenous }\end{array}$ & 330 & 111 & 90 & 80 & 20 & Citrate 10 \\
\hline Ringer's lactate & 280 & - & 130 & 110 & 4 & Bicarb 25 \\
\hline $0.9 \%$ saline & 308 & - & 154 & 154 & - & - \\
\hline
\end{tabular}

${ }^{\star}$ Glucose given with fructose $1 \mathrm{mmol} / 1$ and sucrose $94 \mathrm{mmol} / \mathrm{l}$.

\section{Key recommendations}

All gained consensus. The level of evidence and strength of recommendation follow each statement

- Level of dehydration is assessed using a table modified from WHO criteria (III, C)

- Those with no dehydration (<3\%) should continue with their normal fluids at at least maintenance levels (Va, D)

- Those with mild-moderate dehydration (3-8\%) should have their deficit estimated and replaced over four hours with oral rehydration solution (glucose based and reduced osmolality, 200-250 $\mathrm{mOsm} / \mathrm{l})(\mathrm{I}, \mathrm{A})$

- Oral rehydration solution should be given in small aliquots frequently. If vomiting persists it should be given by nasogastric tube (preferred) or intravenous rehydration commenced (I, A)

- No routine investigations of $U \& E$ are required unless intravenous rehydration is commenced or hypernatraemia is suspected clinically (Va, D)

- Children with mild-moderate and severe dehydration should be admitted to hospital for rehydration (consensus, D)

- Following rehydration (four hours) normal feeds should be recommenced (I, A)

- There is no place for antidiarrhoeal medication (I, A)

the management of acute childhood gastroenteritis, and their side effect profile is unacceptable (reviews of trials ${ }^{25}{ }^{40}(\mathrm{I}, \mathrm{A})$ ).

Recommendation on medication (see table 7)

- Infants and children with acute gastroenteritis should not be treated with antidiarrhoeal agents.

(Level I and Delphi consensus, Grade A recommendation.)

\section{Discussion}

This guideline for the management of the child who presents with acute diarrhoea to hospital was developed using a systematic literature review and formal consensus using a Delphi panel. It is striking that for this type of management guideline the level of published evidence on which recommendations are based is poor. During the Delphi process, 41 statements were made, of which $13 \%$ were based on level I evidence, $25 \%$ on level III, $52 \%$ on level V, and $10 \%$ on textbook recommendation or Delphi panel contributions. The final guideline consists of 34 consensus statements $(83 \%$ of the total presented to the Delphi panel).

This Delphi method of guideline development has several advantages. The use of a nationally selected panel of clinicians allows for a consensus view to be gained on those issues on which published evidence is lacking. Thus a comprehensive guideline can be produced with recommendations on all areas of management, which is likely to be acceptable and practical. It is likely to then need only simple local tailoring prior to being adopted. This method ensures that the guideline is clear on the level of evidence for each recommendation so that the clinician knows which are based on strong evidence from the literature and which on consensus.

There are also potential weaknesses with this approach. For the areas where there is little or no good evidence in the literature the process relies on the opinion of the participating panellists. It is therefore possible to tap into collective error-the whole group managing children in a certain way based on historical practice rather than evidence. The importance of stating the level of evidence for each recommendation is again highlighted, so individual clinicians and local guideline development panels can immediately see which are based on strong evidence and which are not. The method was time consuming, with the whole process taking one year from initiating literature review to implementation of the guideline. It is therefore possible that high quality evidence is published in the intervening period which cannot be included in the recommendations at the time of publication, since it did not go through the Delphi process.

Further research would be beneficial on many of the decision points discussed, for example: the assessment of risk of dehydration in the child in a developed country, outpatient versus inpatient management of rehydration, nasogastric versus oral rehydration, and cereal versus glucose based ORS for rehydration (and palatability) in a developed country.

We intend to review the evidence and consensus on which this guideline is based in approximately three years from the date of its completion (May 1999).

The authors acknowledge Children Nationwide Medical Research Fund for their generous funding of this research, and Jeanette Taylor-Meek for effective administration of the Delphi process. The following Delphi panelists are acknowledged for contributing a great deal of time and effort: Ackland $\mathrm{F}$ (paediatric consultant), Arrowsmith W A (paediatric consultant), Bailey R (A\&E consultant), Barker R (paediatric nurse), Bennett Britton S (paediatric consultant), Boon A W (paediatric consultant), Boyle R (paediatric specialist registrar), Cade A (paediatric specialist registrar), Carter $\mathrm{E}$ (paediatric consultant), Charlton C P J (paediatric consultant (gastroenterology)), Cutting W A M (paediatric consultant), Cutts J (paediatric nurse), Devane S (paediatric consultant), Edge J (paediatric consultant), Ehrhardt P (paediatric consultant), Gleeson E (A\&E specialist registrar), Green C (paediatric consultant), Hewertson J (paediatric consultant), Hodges S (paediatric consultant), Huynh $\mathrm{H}$ (paediatric specialist registrar), Jefferson I (paediatric consultant), Jenkins $\mathrm{H}$ (paediatric consultant (gastroenterology)), Kershaw C (paediatric consultant), Laurent S (paediatric
consultant), Lewis H M (paediatric consultant), Marcovitch H 
(paediatric consultant), McGovern M C (paediatric specialist registrar), McGraw M E (paediatric consultant), McLain B (paediatric consultant), Puntis J (paediatric consultant (gastroenterology)), Rutter N (paediatric consultant), Sajjanhar T (paediatric consultant
(A\&E)), Smith R (paediatric consultant), Smith S (paediatric consultant (A\&E)), Stephens $S$ (paediatric specialist registrar), Sullivan C (paediatric consultant), Thomas S (paediatric specialist registrar), Wells L (paediatric specialist registrar).

\section{Appendix}

Table A1 summarises levels of evidence and grade of recommendation.

Table A1 Levels of evidence and grade of

recommendation

\begin{tabular}{|c|c|c|c|}
\hline Level & $\begin{array}{l}\text { Strength of evidence } \\
\left(\text { adapted from Muir } \text { Gray }^{68} \text { ) }\right.\end{array}$ & Grade & $\begin{array}{l}\text { Grade of } \\
\text { recommendation } \\
\left(\text { Cook et al } l^{69}\right)\end{array}$ \\
\hline I & $\begin{array}{l}\text { Strong evidence from at } \\
\text { least one systematic review } \\
\text { of multiple, well designed } \\
\text { randomised controlled } \\
\text { trials }\end{array}$ & A & $\begin{array}{l}\text { Supported by Level } \\
\text { I evidence and } \\
\text { therefore highly } \\
\text { recommended }\end{array}$ \\
\hline I I & $\begin{array}{l}\text { Strong evidence from at } \\
\text { least one properly } \\
\text { designed randomised } \\
\text { controlled trial of } \\
\text { appropriate size }\end{array}$ & B & $\begin{array}{l}\text { Supported by Level } \\
\text { II evidence, and } \\
\text { therefore } \\
\text { recommended }\end{array}$ \\
\hline I I I & $\begin{array}{l}\text { Evidence from well } \\
\text { designed trials without } \\
\text { randomisation, single } \\
\text { group pre-post, cohort, } \\
\text { time series, or matched } \\
\text { case-control studies }\end{array}$ & C & $\begin{array}{l}\text { Supported by Level } \\
\text { III evidence; several } \\
\text { potential clinical } \\
\text { actions might be } \\
\text { considered } \\
\text { appropriate }\end{array}$ \\
\hline IV & $\begin{array}{l}\text { Evidence from well } \\
\text { designed, } \\
\text { non-experimental studies } \\
\text { from more than one centre } \\
\text { or research group }\end{array}$ & $\mathrm{D}$ & $\begin{array}{l}\text { Supported by Level } \\
\text { IV and V evidence; } \\
\text { the consensus route } \\
\text { would have to be } \\
\text { adopted }\end{array}$ \\
\hline $\mathrm{Va}$ & $\begin{array}{l}\text { Opinions of respected } \\
\text { authorities }\end{array}$ & $\mathrm{D}$ & \\
\hline $\mathrm{Vb}$ & $\begin{array}{l}\text { Clinical evidence, } \\
\text { descriptive studies, or } \\
\text { reports of expert } \\
\text { committees }\end{array}$ & D & \\
\hline
\end{tabular}

1 Djuretic T, Ramsay M, Gay N, et al. An estimate of the proportion of diarrhoeal disease episodes seen by general
practitioners attributable to rotavirus in children under five practitioners attributable to rotavirus in children under five years of age in Engl

2 Armon K, Stephenson TJ, MacFaul R, et al. Determining the common presenting problems to paediatric accident and emergency. Paediatrics Today 1999;7:20.

3 MacFaul R, Jones S, Werneke U. Clinical training experience in district general hospitals. Arch Dis Child 2000;83:39-44.

4 Djuretic T, Ryan M, Wall P. The cost of inpatient care for acute infectious intestinal disease in England from 1991 to 1994. Commun Dis Rep 1996;6:R78-80.

5 Olowokure B, Hawker J, Weinberg J, et al. Deprivation and hospital admission for infectious intestinal diseases. Lancet 1999;353:807-8.

6 Hopkins A. Some reservations about clinical guidelines. Arch Dis Child 1995;72:70-5.

7 Baldassano RN, Liacouras CA. Chronic diarrhoea: a practical approach. Pediatr Clin North Am 1991;38:667-86.

8 Cheney CP, Wong RKH. Acute infectious diarrhoea. Med Clin North Am 1993;77:1169-96.

9 Glass RI, Lew JF, Gangarosa RE, et al. Estimates of morbidity and mortality rates for diarrhoeal diseases in American children. F Pediatr 1991;118:S27-33.

10 Parashar UD, Holman RC, Clarke MJ, et al. Hospitalizations associated with rotavirus diarrhoea in the United States, 1993 through 1995: surveillance based on the new ICD-9-CM rotavirus-specific diagnostic code. $\mathcal{F}$ Infect Di 1998;177:13-17.

11 Office of Population Census and Surveys. Morbidity statistics from general practice, fourth national study, 1991-1992. London: HMSO, 1993.

12 Office for National Statistics. Mortality statistics: childhood, infant and perinatal, 1996, England and Wales. London: The Stationary Office, 1996.

13 Office of Population Census and Surveys. Mid-1993 population estimates for England and Wales. London: HMSO, 1994.

4 Ryan MJ, Ramsay M, Brown D, et al. Hospital admissions attributable to rotavirus infection in England and Wales. $\mathcal{f}$ Infect Dis 1996;174:S12-18.
15 Skirrow MB. A demographic survey of campylobacter, salmonella and shigella infections in England. A Public Health Laboratory Service Survey. Epidemiol Infect 1987; 99:647-57.

16 Rodriguez WJ, Kim HW, Brandt CD, et al. Rotavirus gastroenteritis in the Washington, D.C. area. Incidence of cases resulting in admission to the hospital. Am $\mathcal{F}$ Dis Child 1980;134:777-9.

17 Senturia YD. Epidemiology of rotavirus gastroenteritis. 7 Epidemiol Community Health 1986;40:236-9.

18 Fleischer GR. Pediatric emergency medicine, 4th edn. Baltimore: Williams and Wilkins, 1997.

19 Macdonald IA, Beattie TF. Intussusception presenting to a paediatric accident and emergency department. 7 Accid Emerg Med 1995;12:182-6.

20 Milford DV, Taylor CM, Guttridge B, et al. Haemolytic uraemic syndromes in the British Isles 1985-8: association with verocytotoxin producing Escherichia coli. Part 1: clinical and epidemiological aspects. Arch Dis Child 1990;65:716-21

21 Reynolds SL, Jaffe DM. Children with abdominal pain: evaluation in the pediatric emergency department. Pediatr Emerg Care 1990;6:8-12.

22 Bhattacharya SK, Bhattacharya MK, Manna B, et al. Risk factors for development of dehydration in young children with acute watery diarrhoea: a case-control study. Acta Paewith acute watery dia.

23 Fuchs SC, Victora CG, Martines J. Case-control study of risk of dehydrating diarrhoea in infants in vulnerable period after full weaning. $B M \mathcal{F}$ 1996;313:391-4

24 Faruque ASG, Mahalanabis D, Islam A, et al. Breast feeding and oral rehydration at home during diarrhoea to prevent dehydration. Arch Dis Child 1992;67:1027-9.

25 Murphy MS. Guidelines for managing acute gastroenteritis based on a systematic review of published research. Arch Dis Child 1998;79:279-84.

26 Duggan C, Refat M, Hashem M, et al. How valid are clinical signs of dehydration in infants. F Pediatr Gastroenterol Nutr 1996;22:56-61.

27 Mackenzie A, Barnes G, Shann F. Clinical signs of dehydration in children. Lancet 1989;ii:605-7.

28 Ironside AG, Tuxford AF, Heyworth B. A survey of infantile gastroenteritis. BMF 1970;3:20-4

29 Santosham M, Brown KH, Sack RB. Oral rehydration therapy and dietary therapy for acute childhood diarrhoea. Pediatr Rev 1987;8:273-8.

30 Saavedra JM, Harris GD, Li S, Finberg L. Capillary refilling (skin turgor) in the assessment of dehydration. Am $\mathcal{F}$ Dis Child 1991;145:296-8.

31 Baraff LJ, Bass JW, Fleisher GR, et al. Practice guideline for the management of infants and children 0 to 36 months of age with fever without source. Agency for Health Care Policy and Research. Ann Emerg Med 1993;22:1198-210.

32 Gorelick MH, Shaw KN, Baker MD. Effect of ambient temperature on capillary refill in healthy children. Pediatrics 993;92:699-702.

33 Msengi AE, Phillips AD, Risdon RA, Walker-Smith JA. Travellers' diarrhoea among children returning to the United Kingdom from visits abroad. Ann Trop Paediatr $1988 ; 8: 173-80$.

34 Hutchins P, Hindocha P, Phillips A, Walker-Smith J. Traveller's diarrhoea with a vengeance in children of UK mmigrants visiting their parental homeland. Arch Dis Child 1982;57:208-11.

35 DeWitt TG, Humphrey KF, McCarthy P. Clinical predictors of acute bacterial diarrhoea in young children. Pediatrics 1985;76:551-6.

36 Finkelstein JA, Schwartz JS, Torrey S, Fleischer GR. Common clinical features as predictors of bacterial diarrhoea in infants. Am f Emerg Med 1989;7:469-73.

37 Conway SP, Phillips RR, Panday S. Admission to hospital with gastroenteritis. Arch Dis Child 1990;65:579-84.

38 McNeely WS, Dupont HL, Mathewson JJ, et al. Occult blood versus fecal leukocytes in the diagnosis of bacterial diarrhoea: a study of US travelers to Mexico and Mexican children. Am F Trop Med Hyg 1996;55:430-3.

39 Singh T, Verma M, Chatwal J, et al. Predictive utility of clinical and stool parameters in bacterial diarrhoea in children. Indian F Med Sci 1995;49:285-90.

40 American Academy of Pediatrics, Provisional Committee on Quality Improvement Subcommittee on Acute Gastroenteritis. Practice parameter: the management of acute gastroenteritis in young children. Pediatrics 1996;97:424-36.

41 Holliday M. The evolution of therapy for dehydration: should deficit therapy still be taught? Pediatrics 1996;98: $171-7$.

42 Meyers A. Fluid and electrolyte therapy for children. Curr Opin Pediatr 1994;6:303-9.

43 Goepp JG, Katz SA. Oral rehydration therapy. Am Fam Physician 1993;47:843-51

4 Booth I, Cunha Ferreira R, Desjeux JF, et al. Recommendations for composition of oral rehydration solutions for the children of Europe. Report of an ESPGAN working group. 7 Pediatr Gastroenterol Nutr 1992;14:113-15.

45 Walker-Smith JA, Sandhu BK, Isolauri E, et al. Recommendations for feeding in childhood gastroenteritis. Medical position paper Guidelines prepared by the ESPGAN working group on acute diarrhoea. $\mathcal{F}$ Pediatr Gastroenterol Nutr 1997;24:619-20.

46 Fontaine O. Multicentre evaluation of reduced-osmolarity oral rehydration salts solution. International Study Group on reduced-osmolarity ORS solutions. Lancet 1995;345: $282-5$. 
47 Rautanen T, El-Rhadhi S, Vesikari T. Clinical experience with a hypotonic oral rehydration solution in acute a. Acta Paediatr 1993;82:52-4.

48 Gore SM, Fontaine O, Pierce NF. Impact of rice based oral rehydration solution on stool output and duration of diarrhoea: meta-analysis of 13 clinical trials. BMF 1992; 304:287-91.

49 Santosham M, Daum RS, Dillman L, et al. Oral rehydration therapy of infantile diarrhoea: a controlled study of well nourished children hospitalized in the United States and Panama. N Engl f Med 1982;306:1070-6.

50 Tamer AM, Friedman LB, Maxwell SRW, et al. Oral rehydration of infants in a large urban U.S. medical centre. f Pediatr 1985;107:14-19.

51 Vesikari T, Isolauri E, Baer M. A comparative trial of rapid oral and intravenous rehydration in acute diarrhoea. Acto Paediatr Scand 1987;76:300-5.

52 Sharifi J, Ghavami F, Nowrouzi Z, et al. Oral versus intravenous rehydration therapy in severe gastroenteritis. Arch Dis Child 1985;60:856-60.

53 Pizarro D, Posada G, Levine M. Hypernatraemic diarrhoeal dehydration treated with "slow" (12 hour) oral rehydration dehydration treated with "slow" (12 hour) oral rehydration

54 Mackenzie A, Barnes G. Randomised controlled trial comparing oral and intravenous rehydration therapy in children with diarrhoea. BMF 1991;303:393-6.

55 Brown KH, Peerson JM, Fontaine O. Use of nonhuman milks in the dietary management of young children with acute diarrhoea: a meta-analysis of clinical trials. Pediatric 1994;93:17-27

56 Khin-Maung-U, Nyunt-Nyunt-Wai, Myo-Khin, et al. Effect on clinical outcome of breast feeding during acute diarrhoea. BM7 1985;290:587-9.

57 Conway SP, Newport MJ. Are all hospital admissions for acute gastroenteritis necessary? F Infect 1994;29:5-8.

58 To T, Feldman W, Young W, Malony SL. Hospitalization rates of children with gastroenteritis in Ontario. Can $\mathcal{F} P u b-$ lic Health 1996;87:62-5.

59 Fitzgerald M, McGee HM. Psychological health status of mothers and the admission of children to hospital for gasmothers and the admission of children

60 Nelson JD, Kusmiesz H, Hinton Jackson L, Woodman E. Treatment of Salmonella gastroenteritis with ampicillin, amoxicillin or placebo. Pediatrics 1980;65:1125-30.

61 Jenkins HR, Ansari BM. Management of gastroenteritis. Arch Dis Child 1990;65:939-41.

62 Ellis ME, Watson B, Mandal BK, et al. Contemporary gastroenteritis of infancy: clinical features and prehospital management. BMF 1984;288:521-3.

63 Gavin N, Merrick N, Davidson B. Efficacy of glucose-based oral rehydration therapy. Pediatrics 1996;98:45-51.

64 Santosham M, Greenough W. Oral rehydration therapy: a global perspective. $\mathcal{F}$ Pediatr 1991;118:S44-51.

65 Rudolph A, Hoffman J, Rudolph C. Rudolph's pediatrics, 20th ed. London: Prentice Hall International, 1996.

66 WHO. World Health Organisation. A manual for the treatment of diarrhoea. Programme for the control of diarrhoeal diseases. of diarrhoea. Programme for the control of diarrhoeal diseases.

67 Sandhu B, Isolauri E, Walker-Smith J, et al. Early feeding in childhood gastroenteritis. A multicentre study on behalf of the European Society of Paediatric Gastroenterology and Nutrition working group on acute diarrhoea. F Pediatr Gastroenterol Nutr 1997;24:522-7.

68 Muir Gray JA. Evidence-based healthcare. London: Churchil Livingstone, 1997.

69 Cook D, Guyatt G, Laupacis A, Sackett D. Rules of evidence and clinical recommendations on the use of antithrombotic agents. Chest 1992;102:305S-311S.

\section{Commentary}

No doctor can hope to keep up to date with the literature across a broad spectrum of practice. National guidelines are helpful where they bring together all the evidence from research and synthesise it into a series of recommendations showing the strength of that evidence. Dr Armon and colleagues have used a formal consensus process to provide guidance, and this raises a number of important questions. It happens that there are also recent guidelines on acute diarrhoea management published by Murphy in $1998,{ }^{1}$ and by the American Academy of Paediatrics (AAP) in $1996 .{ }^{2}$ If guidelines are to provide truly evidence based recommendations, they must be developed rigorously. How do these three guidelines measure up to the standards published by the Royal College of Paediatrics and Child Health? ${ }^{3}$

They are all based on a detailed review of the literature, and two contain explicit levels of evidence for the recommendations. They were not conducted with the rigour of the systematic reviews in the Cochrane database. For example, the review of Dr Armon et al did not include textword searching, and none included hand searching through journals not covered by the electronic databases. There was no attempt to establish whether unpublished trials exist: publication bias can result when journals are more likely to publish trials with positive results. The AAP guideline was supplemented by a technical report and focused on three specific aspects of management.

The consensus guideline of Dr Armon et al involved consultants from several specialties, nurses, and specialist registrars. This is important in ensuring that the perspectives of all those involved contribute to the guidance. However, with only two nurses on the panel, the Delphi process would have allowed consensus to be achieved, even when both nurses disagreed. The lack of any primary care or parental input to the process undermines the section on admission criteria, for which research evidence appears to be lacking. The assistance of parents with recent experience of managing acute diarrhoea in their children would have been most valuable in formulating written material for parents.

The key message to emerge from all three guidelines is the safety and effectiveness of oral rehydration solutions, even in children with moderate (up to $8 \%$ ) dehydration without shock. Additionally, that administration of the calculated deficit over a few hours is simple and effective. Crucial to achieving success with oral rehydration solution is the time that it takes carers to administer. All three guidelines recommend the correction of dehydration orally over a period of four hours. This would mean for some infants and children a rate of up to $80 \mathrm{ml} / \mathrm{kg}$ over four hours. However, in none of six controlled trials that I looked up, ${ }^{4-9}$ was this rate of oral administration attempted, and in only one ${ }^{7}$ was it achieved. Is this recommendation therefore actually consistent with the evidence, or indeed better than six or eight hours for achieving rehydration? It was rated an A grade in Dr Armon and colleagues' guideline.

Where does this leave the UK practising paediatrician? Given the limitations of the three guidelines, there is a risk that important evidence may be missing or inadequately interpreted. We still need a well conducted evidence based guideline, involving all professional groups, primary care and parents, and based on a rigorous literature review. However, the studies that support these guidelines are compelling, and we should not wait before using a multiprofessional approach to getting oral rehydration therapy into practice at the local level. Read all three guidelines as a starting point in reviewing or developing local guidelines, but check back to the key original publications. I will leave it to you, the reader, to judge how much extra value you get from Dr Armon and colleagues' consensus statements.

HARRY BAUMER

Consultant Paediatrician, Derriford Hospital,

Plymouth, Devon, UK 
1 Murphy MS. Guidelines for managing acute gastroenteritis based on a systematic review of published research. Arch based on a systematic review

2 American Academy of Pediatrics, Provisional Committee on Quality Improvement Subcommittee on Acute Gastroenteritis. Practice parameter: the management of acute gastroenteritis in young children. Pediatrics 1996;97:42436.

3 RCPCH. Standards for development of clinical guidelines in paediatrics and child health: role of the Royal College of Paediatrics and Child Health. London: RCPCH, December 1998

4 Santosham M, Burns, B, Nadkarni V, et al. Oral rehydration therapy for acute diarrhea in ambulatory children in the United States: a double-blind comparison of four differen solutions. Pediatrics 1985;76:159-66.
5 Listernick R, Zieseri E, Davis AT. Outpatient oral rehydration in the United States. Am F Dis Child 1986;140:211-15.

6 Santosham M, Daum RS, Dillman L, et al. Oral rehydration therapy of infantile diarrhoea: a controlled study of well nourished children hospitalized in the United States and Panama. N Engl f Med 1982;306:1070-6.

7 Tamer AM, Friedman LB, Maxwell SRW, et al. Oral rehydration of infants in a large urban U.S. medical centre. f Pediatr 1985;107:14-19.

8 Vesikari T, Isolauri E, Baer M. A comparative trial of rapid oral and intravenous rehydration in acute diarrhoea. Acta Paediatr Scand 1987;76:300-5.

9 Sharifi J, Ghavami F, Nowrouzi Z, et al. Oral versus intravenous rehydration therapy in severe gastroenteritis. Arch Dis Child 1985;60:856-60.

\section{Rapid responses}

Letters on the following papers have been published recently as rapid responses on the $A D C$ website. To read these letters visit www.archdischild.com and click on "Read eLetters":

Bronchoconstriction following nebulised colistin in cystic fibrosis. Cunningham S, Prasad A, Collyer L, et al. Arch Dis Child 2001;84:432-3.

Adrenaline syringes are vastly over prescribed. Unsworth DJ. Arch Dis Child 2001;84:410-11.

An audit of RCP guidelines on DMSA scanning after urinary tract infection. Deshpande PV, Verrier Jones K. Arch Dis Child 2001;84:324-7.

Does height influence progression through primary school grades? Wake $M$, Coghlan $\mathrm{D}$, Hesketh $\mathrm{K}$. Arch Dis Child 2000;82:297-301.

If you would like to post an electronic response to these or any other articles published in the journal, please go to the website, access the article in which you are interested, and click on "eLetters: Submit a reponse to this article" in the box in the top right hand corner. 